\title{
Electrophysiological assessment in spinal intradural tumors
}

\author{
(D) Soner Yaşar, (1) Alparslan Kırık \\ University of Health Sciences Turkey, Gülhane Training and Research Hospital, Clinic of Neurosurgery, Ankara, Turkey
}

\section{Date submitted:}

25.11.2019

Date accepted:

16.12.2019

Online publication date:

15.06.2020

\section{Corresponding Author:}

Soner Yaşar MD, University of Health

Sciences Turkey, Gülhane Training

and Research Hospital, Clinic of

Neurosurgery, Ankara, Turkey

dr.soneryasar@gmail.com

ORCID:

orcid.org/0000-0001-9331-0144

Keywords: Spinal tumor, intradural, surgery, electrophysiology

\begin{abstract}
Aims: To present our spinal intradural tumor series and to evaluate the reliability of electrophysiological assessment in patients treated for these tumors.

Methods: We retrospectively evaluated the data of patients treated for spinal intradural tumor between 2010 and 2019. The demographic, surgical and histological features of patients were evaluated and compared with their pre- and postoperative electrophysiological data. Somatosensory evoked potentials (SEP) were used as electrophysiological test.
\end{abstract}

Results: A total of 69 patients with spinal intradural tumor was evaluated. Thirty-one of them had extramedullary and 38 had intramedullary tumor. The mean age was 48.3 years for extramedullary and 26.3 years for intramedullary tumors. In preoperative period, SEP was prolonged in 25 patients with intramedullary tumor while it was prolonged in 8 patients with extramedullary tumor. In postoperative period, recovery in SEP values was detected in 5 of 25 patients with intramedullary tumor but it was observed in 7 of 8 patients with extramedullary tumor.

Conclusions: Electrophysiological evaluation is a safe and reliable method to assess the patients surgically treated for spinal intradural tumor. It is an objective method to evaluate the neurological recovery of patients with extramedullary tumor.

\section{Introduction}

Tumors of the spine and spinal cord make up about $15 \%$ of all central nervous system (CNS) tumors (1). Its annual incidence is $2-10$ per 100,000 people. Spinal tumors are divided into two groups as intradural and extradural (2). These tumors are mostly located in the extradural region (55-60\%) and cancer metastases are the most common type of extradural spinal tumors (3). Spinal intradural tumors are rarer and more difficult to diagnose. These tumors may develop in adults as well as in children (4). The frequent symptoms are back and/or neck pain (based on the site of tumor), radicular pain, weakness, paresthesia, gait disturbances, and bowel and bladder dysfunctions (5). Common diagnostic methods for spinal tumors are computed tomography (CT) and magnetic resonance imaging (MRI) (3).

Intradural tumors are categorized into two as intramedullary and extramedullary depending on the relationship with the spinal cord $(5,6)$. Extramedullary tumors are rare. They constitute nearly $40-45 \%$ of all tumors of the spine. They are separated from intramedullary tumors because of their extra axial location.
Extramedullary tumors usually occur in the age range of $45-50$ and have male predominance. Its annual incidence is 0.4 per 100,000 people $(7,8)$. Most frequent tumors of the extramedullary region are meningioma, nerve sheath tumors and filum terminale ependymomas (7-9). Diagnosis is made by contrast-enhanced T1 and T2-weighted MRI. Main treatment is surgery and total resection is usually possible using standard microsurgical techniques. The results of surgery in extramedullary tumors are often promising and satisfactory $(6,9,10)$.

Intramedullary tumors are less common spinal cord tumors, potentially causing serious neurological deficits, poor quality of life, and even death (11). The rate of all primary spinal tumors is 20$30 \%$ (12). $80 \%$ of these tumors are glial tumors (12). Each tumor has its own characteristics and its behavior varies depending on its radiological and clinical features (13). Diagnosis is often difficult. T1 and T2-W spinal MRI is the gold standard for the diagnosis of intramedullary tumors. Transverse myelitis, multiple sclerosis and other autoimmune and inflammatory diseases of the spinal cord are in the differential diagnosis of these 
tumors. Treatment is primarily surgical $(14,15)$. Preoperative neurological condition and histopathological features of the tumor are the factors that determine further treatment. Early diagnosis provides rapid treatment protocols $(16,17)$.

Electrophysiologic evaluation is performed preoperatively and postoperatively for all spinal tumors (18). This evaluation is an objective method especially for postoperative neurological follow-up of patients. Although sensory evoked potentials (SEP) are generally used, motor evoked potentials (MEP) are also important. Currently, the most common median and tibial nerve SEPs are measured (19). Their latencies and amplitudes are measured and evaluated. Prolonged SEP latencies are an important clinical marker especially in spinal intramedullary tumors. In addition, decrease in amplitude in cortical responses as a result of median and tibial stimuli is the finding supporting neurological effect. Changes in these parameters following the surgery suggest that patients may be evaluated more objectively from a neurological point of view (18).

The aims of our study were to analyze pre- and postoperative SEP records of spinal intradural tumor patients and to compare the changes with the clinical outcomes.

\section{Methods}

The ethical approval of this study was obtained from the Ethics Committee of Keçiören Training and Research Hospital (date: 13.02.2017 and no: 1332). A total of 157 spinal tumor cases operated in our clinic between 2010 and 2019 and their data were reviewed retrospectively. MRI was used in all patients and CT was performed in patients with bone involvement or calcification. Contrast enhanced images were preferred for the detection of tumors. The tumor was intradural in 69 (44\%) of 157 patients and these patients were examined. Laminectomy/ laminotomy was performed with standard midline approach and tumor resection was performed using microsurgical techniques. Myelotomy was performed for intramedullary tumors. Extramedullary tumors were removed after dural opening. Meticulous microsurgical dissection was performed during the tumor removal in order to protect the spinal cord and spinal roots. The radiological, electrophysiological and clinical data of these 69 patients were reviewed retrospectively. All patients underwent electrophysiological evaluation with SEPs preoperatively and postoperatively. Integrated electrical stimulators and electrodes (Medtronic Dantec ${ }^{\circledR}$, Denmark) were used for electrophysiological assessment. Latency and amplitude of the posterior tibial and median nerve evoked sensory potentials were measured in all patients. The stimuli were given from the posterior tibial and median nerves. Responses were recorded from the somatosensorial cortex. P37 and N20 responses were used for median and posterior tibial nerves respectively. These SEP results were compared with preoperative results. In addition, intraoperative neuromonitorization (IONM) was performed during the operation. In IONM, MEP and free-running methods were applied. MEP recordings were performed before, during and just after the tumor removal. We evaluated the neurological condition of each patient prior to surgery, 24 hours following the surgery, and then three months after the discharge. Postoperative SEP recordings and neurological outcomes were compared. The mean follow-up period was 1.2 years.

\section{Results}

Sixty-nine patients who were operated for spinal intradural tumor during the last 10 years and who had preoperative and postoperative electrophysiological test records were included in this study. There were extramedullary tumors in 31 patients and intramedullary tumors in 38 patients (Table 1). The most frequent location of intramedullary tumors was cervical region $(n=13)$. Thoracic spine was the frequent site of extramedullary tumors $(n=12)$. The most common extramedullary tumor was meningioma and was detected in 15 patients (Figure 1). This was followed by schwannoma, neuroepithelial cyst, neuroenteric cyst and lymphoma metastasis. The most common intramedullary tumor was ependymoma and was observed in 23 patients. This was followed by astrocytoma (Figure 2),

\begin{tabular}{ll}
\hline $\begin{array}{l}\text { Table } 1 . \\
\text { features, tumor locations and histological types }\end{array}$ \\
\hline Variable & Number (\%) \\
\hline Sex & \\
\hline Female & $30(43.5 \%)$ \\
\hline Male & $39(56.5 \%)$ \\
\hline Total & $69(100 \%)$ \\
\hline Location & \\
\hline Extramedullary & $31(44.9 \%)$ \\
\hline Intramedullary & $38(55.1 \%)$ \\
\hline Total & $69(100 \%)$ \\
\hline Intramedullary tumors & \\
\hline Ependymoma & $23(60.5 \%)$ \\
\hline Astrocytoma & 5 \\
\hline Lipoma & 4 \\
\hline Epidermoid tm & 3 \\
\hline Paraganglioma & 2 \\
\hline Ganglioglioma & 1 \\
\hline Total & $38(100 \%)$ \\
\hline Extramedullary tumors & $15(48.4 \%)$ \\
\hline Meningioma & 12 \\
\hline Schwannoma & 1 \\
\hline Neuroepithelial cyst & 1 \\
\hline Neuroenteric cyst & 2 \\
\hline Lymphoma metastasis & $31(100 \%)$ \\
\hline Total & \\
\hline
\end{tabular}


lipoma, epidermoid tumor, paraganglioma, ganglioglioma. In astrocytomas, 2 patients had the diagnosis of glioblastoma and they died in follow-up period. The mean age of patients with intradural extramedullary tumors was 48.3 years and ranged from 2 to 75 years. Nineteen of these patients were female and 12 were male. The mean age of patients with intradural intramedullary tumors was 26.3 years and ranged from 0 to 66 years. Eleven of these patients were female and 27 were male (Table 1).

No neurological deterioration was observed in any patient. Neurological improvement was observed in 28 (90.3) of 31 patients with extramedullary tumor while it was seen in $23(60.5 \%)$ of 38 patients with intramedullary tumor. In the preoperative period, 25 of 38 patients with intramedullary tumors had prolonged SEP responses, whereas 8 of 31 patients with extramedullary tumors had longer responses. Postoperatively, SEP responses were improved in $5(20 \%)$ of 25 patients in the intramedullary group and $7(87.5 \%)$ of 8 patients in the extramedullary group. The clinical and electrophysiological improvement is better in extramedullary tumor group than the intramedullary tumor group.

Two patients with intramedullary tumor died in the postoperative period. The histological diagnosis of these patients was glioblastoma and the location of tumor in both patients was thoracic spinal cord. Cerebrospinal fluid collection after surgery

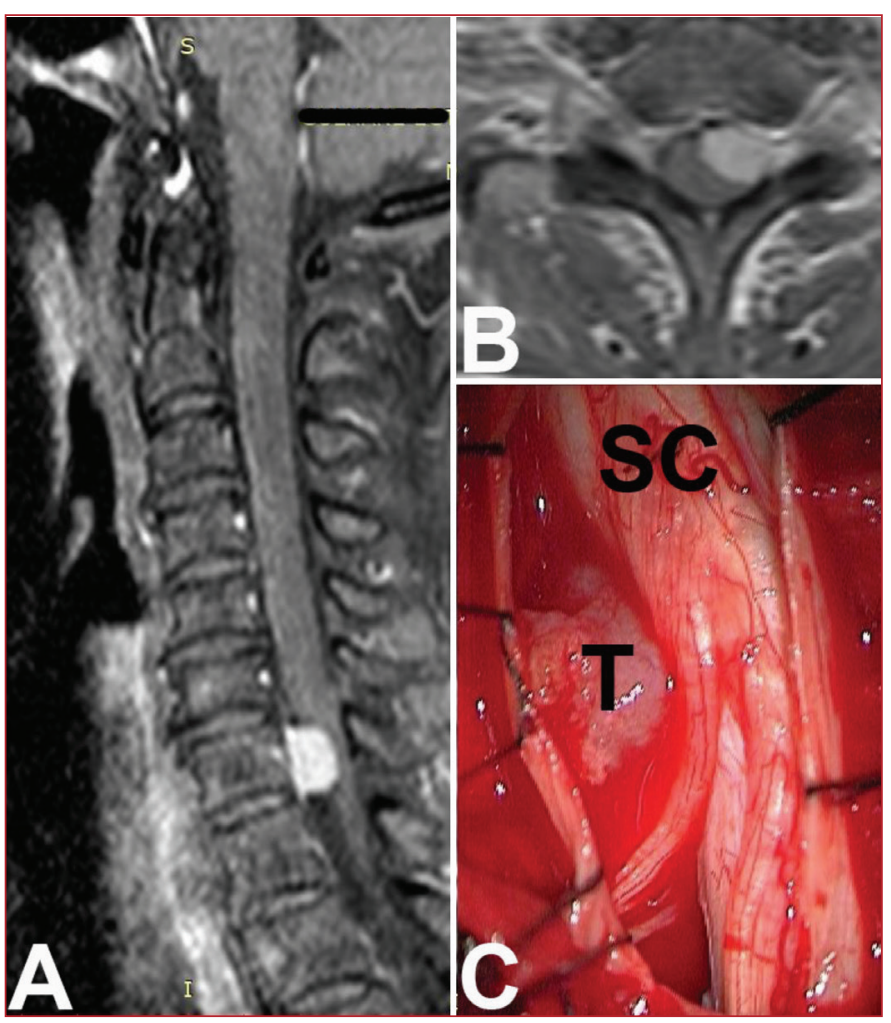

Figure 1. T1-W sagittal (A) and axial (B) magnetic resonance imaging of a patient with intradural extramedullary tumor. It was removed using posterior approach $(\mathrm{C})$ and the histological diagnosis was meningioma T: Tumor, SC: Spinal cord was occurred in 4 patients but resolved in the long-term followup period.

\section{Discussion}

Preoperative and postoperative electrophysiological evaluation of spinal intradural tumors is an objective method for evaluating the outcomes of surgery. In this retrospective study, we analyzed the results of 69 patients with spinal intradural tumor. We found that the electrophysiological improvement was correlated with clinical improvement especially in intradural extramedullary tumors. We also emphasized that pre- and postoperative electrophysiological assessment of the patients is a reliable method to predict the outcome of surgery.

Spinal tumors are rare malignancies that can seldom be fatal but usually cause serious morbidity (2). The spine and spinal cord are the most common sites of neoplasia after the brain in the CNS. However, not all spinal tumors have the same characteristics (3). They are a heterogeneous group of tumors (1). Therefore, classifications were made according to different characteristics. The most accepted classification is the classification based on the location of tumor. Spinal tumors are divided into two as intradural and extradural according to their relationship with the dura mater. Intradural tumors are tumors located within the dura mater and have no direct relationship with the spine and vertebrae. Extradural tumors are tumors

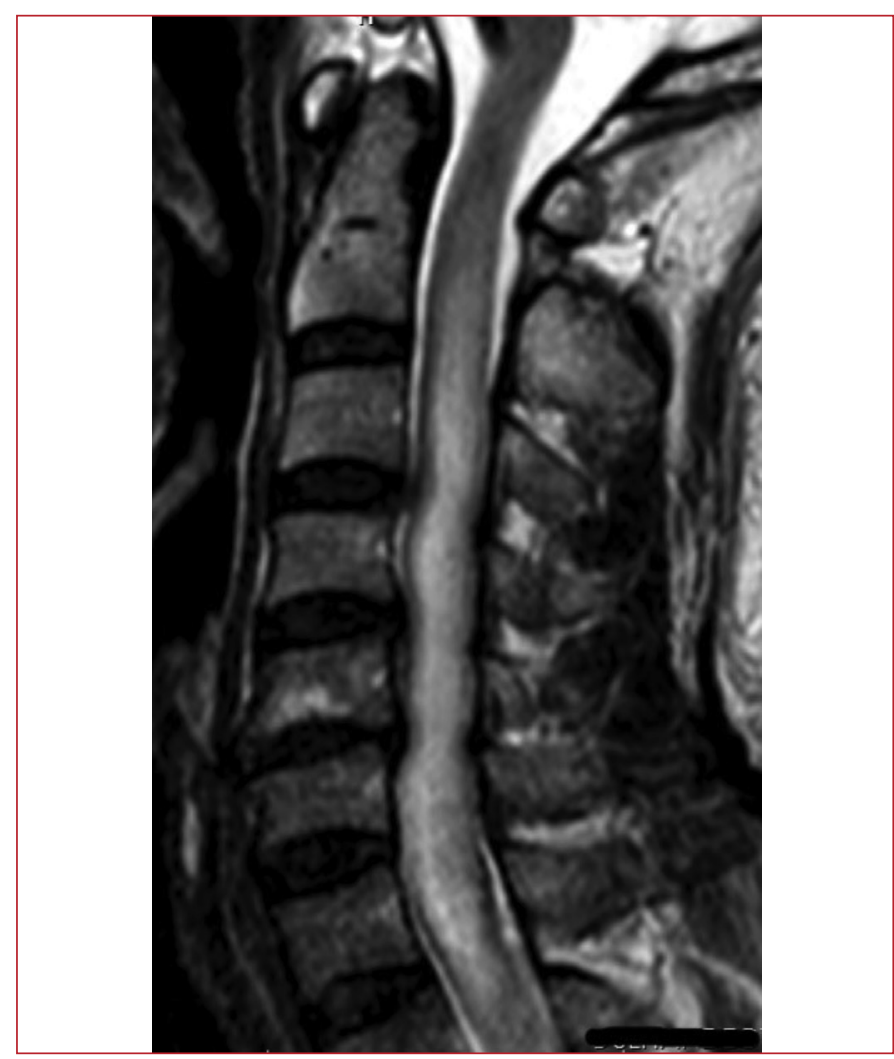

Figure 2. T2-W sagittal magnetic resonance imaging of a patient with cervical intradural intramedullary tumor. The patient underwent surgical treatment and the histological diagnosis was anaplastic astrocytoma 
located outside the dura mater and usually involve the spine and its elements. Intradural tumors are classified as intramedullary (located within the spinal cord) and extramedullary (located outside the spinal cord) according to the medulla spinalis (spinal cord) in the dura mater. Extramedullary tumors are meningiomas and schwannomas originating from dura mater or spinal roots. Intramedullary tumors are usually glial origin and astrocytomas and ependymomas are the most common types of tumor. In our series of 69 intradural tumors, the most common intramedullary tumors were ependymomas $(60 \%)$ and astrocytomas (13\%) followed by lipoma, epidermoid tumor, paraganglioma and ganglioglioma. The most common extramedullary tumors were meningiomas (48\%) and schwannomas (38\%) followed by neuroepithelial cysts, neuroenteric cysts and metastases.

Ottenhausen et al. (6) stated that technological improvements in radiological and electrophysiological techniques, less invasive methods as well as radiation therapy provide better clinical results in spinal tumors located intradurally. They also pointed out that the clinical results of intramedullary malignant spinal tumors are still poor. Ahn et al. (7) reported the results of 11 patients with intradural extramedullary tumors and they emphasized that the level of neurological symptoms was corresponding to the amount of tumor within the intradural space. They also recommended aggressive surgical excision in patients with long-term symptoms or serious neurological deficits. In our series, we have similar results with Ahn et al. (7) and the clinical symptoms of our patients with extramedullary tumors improved rapidly, as well as electrophysiological tests were also improved gradually after surgery.

Electrophysiological tests are widely used in the diagnosis of spinal tumors $(18,19)$. Although MRI and CT are the gold standard in the diagnosis of spinal tumors, electrophysiological tests are useful methods to objectively assess the neurological condition of the patients (3). Especially SEP is frequently used before surgery. Evoked potentials can be defined as the electrical activities of the CNS in response to short sensory stimuli. SEPs are usually measured from the posterior tibial and median nerves and response from the cortex is measured. SEP is often used in the disorders of brain, spinal cord or nerve root and diseases. SEPs may help to identify lesions on any part of somatosensorial pathways. However, the SEP findings should be interpreted together with the neurological examination and radiological imaging results (19). Although MEP may also be used in the diagnosis of spinal tumors, it is generally not preferred preoperatively because it is more difficult and complicated to perform and interpret, but it is used in IONM (20-22). Pusat et al. (19) analyzed the results of 30 patients and concluded that the latency of tibial nerve response may be prolonged in the early time period after spinal intradural tumor surgery. They also pointed out that electrophysiological findings are not predictive for patients with spinal tumor. Ishida et al. (22) reported the significance of IONM for the resection of intradural extramedullary spinal tumors to anticipate the possible neurological disturbances in a 6-month follow-up period after surgery. Meanwhile, SEPs are more easily and widely used both pre- and postoperatively. In our series, 69 patients with intradural tumors underwent SEP preoperatively and postoperatively and the results were recorded. We also performed IONM in all patients. In the preoperative period, 25 of 38 patients with intramedullary tumors had prolonged SEP responses, whereas 8 of 38 patients with extramedullary tumors had longer responses. Postoperatively, SEP responses were improved in 5 of 25 patients in the intramedullary group and 7 of 8 patients in the extramedullary group. These improvements were in parallel with the improvement in the neurological condition of the patients. In addition, no electrophysiological deterioration was observed during the surgery for extramedullary or intramedullary tumors.

\section{Conclusion}

Electrophysiological evaluation of spinal intradural tumors either in preop- or postoperative period is very important. This is also indispensable during the surgery. Electrophysiologic tests are useful for objective neurological evaluation of the patients especially in the postoperative follow-up period.

\section{Ethics}

Ethics Committee Approval: The ethical approval of this study was obtained from the Ethics Committee of Keçiören Training and Research Hospital (date: 13.02.2017 and no: 1332).

Informed Consent: Retrospective study.

Peer-review: Externally peer-reviewed.

\section{Authorship Contributions}

Concept: S.Y., A.K., Design: S.Y., Data Collection or Processing: A.K., Analysis or Interpretation: A.K., S.Y., Literature Search: S.Y., Writing: S.Y.

Conflict of Interest: No conflict of interest was declared by the authors.

Financial Disclosure: The authors declared that this study received no financial support.

\section{References}

1. Özdemir NG, Bıtırak G, Antar V, Kubilay F, Kılıç K. Spinal tümörler: Kırkbeş olguda retrospektif analiz. İstanbul Med J. 2014;15:101-103.

2. Kaptan H, Kasımcan Ö, Çakıroğlu K, Kılıç C. Spinal tümörler. Sinir Sistemi Cerrahisi Derg. 2008;1:59-66. 
3. Temiz C, Kural C, KırıkA, et al. Spinal tumors and outcomes of surgical treatment: A retrospective study. Firat Med J. 2011;16:179-185.

4. Baysefer A, Akay KM, Izci Y, Kayali H, Timurkaynak E. The clinical and surgical aspects of spinal tumors in children. Pediatr Neurol. 2004;31:261-266.

5. Kim WJ, Koo JY, Bae KW, et al. Clinical characteristics and surgical results of spinal intradural tumor. J Korean Soc Spine Surg. 2011;18:43-50.

6. Ottenhausen M, Ntoulias G, Bodhinayake I, et al. Intradural spinal tumors in adults-update on management and outcome. Neurosurg Rev. 2019;42:371-388.

7. Ahn Dk, Park HS, Choi DJ, Kim KS, Kim TW, Park SY. The surgical treatment for spinal intradural extramedullary tumors. Clin Orthop Surg. 2009;1:165-172.

8. Koeller KK, Shih RY. Intradural extramedullary spinal neoplasms: Radiologic-pathologic correlation. Radiographics. 2019;39:468-490.

9. Gezen F, Kahraman S, Canakci Z, Bedük A. Review of 36 cases of spinal cord meningioma. Spine (Phila Pa 1976). 2000;25:727-731.

10. Gezercan Y, Bilgin E, Çavuş G, Açık V, Karaörs H, Ökten Al. Spinal meningiomas: 24-Case clinical series. Pam Med J. 2017;10:228-233.

11. Bhatti SN, Khan SA, Raja RA, et al. Outcome of intramedullary spinal cord tumors: experience with 18 patients operated at Ayub Teaching Hospital, Abbottabad. J Ayub Med Coll Abbottabad. 2010;22:15-17.

12. Manzano G, Green BA, Vanni S, Levi AD. Contemporary management of adult intramedullary spinal tumorspathology and neurological outcomes related to surgical resection. Spinal Cord. 2008;46:540-546.

13. Taricco MA, Guirado VM, Fontes RB, Plese JP. Surgical treatment of primary intramedullary spinal cord tumors in adult patients. Arq Neuropsiquiatr. 2008;66:59-63.
14. Bakhshi SK, Waqas M, Shakaib B, Enam SA. Management and outcomes of intramedullary spinal cord tumors: A single center experience from a developing country. Surg Neurol Int. 2016;7(Suppl 23):617-622.

15. Shrivastava RK, Epstein FJ, Perin NI, Post KD, Jallo GI. Intramedullary spinal cord tumors in patients older than 50 years of age: Management and outcome analysis. J Neurosurg Spine. 2005;2:249-255.

16. Khalid S, Kelly R, Carlton A, et al. Adult intradural intramedullary astrocytomas: a multicenter analysis. J Spine Surg. 2019;5:19-30.

17. Epstein FJ, Farmer JP, Freed D. Adult intramedullary spinal cord ependymomas: The result of surgery in 38 patients. $\mathrm{J}$ Neurosurg. 1993;79:204-209.

18. İzci Y. Spinal tümörlerde nöromonitörizasyon. Turkiye Klinikleri J Neurosurg-Special Topics. 2017;7:88-94.

19. Pusat S, Kural C, Solmaz I, et al. Comparison of electrophysiological outcomes of tethered cord syndrome and spinal intradural tumors: A retrospective clinical study. Turk Neurosurg. 2017;27:797-803.

20. Costa P, Bruno A, Bonzanino M, et al. Somatosensory and motor-evoked potential monitoring during spine and spinal cord surgery. Spinal Cord. 2007;45:86-91.

21. MalhotraNR, Shaffrey CI. Intraoperativeelectrophysiological monitoring in spine surgery. Spine (Phila Pa 1976). 2010;35:2167-2179.

22. Ishida W, Casaos J, Chandra A, et al. Diagnostic and therapeutic values of intraoperative electrophysiological neuromonitoring during resection of intradural extramedullary spinal tumors: a single-center retrospective cohort and meta-analysis. J Neurosurg Spine. 2019:1-11. 